EDITOR'S

\section{See Editorial, p 833}

- Details of the search strategy and additional tables and figures are published online only at http://thorax.bmj.com/content/ vol64/issue10

${ }^{1}$ Centre de recherche de I'Institut universitaire de cardiologie et de pneumologie de Québec (Hôpital Laval), Québec, Canada; ${ }^{2}$ Service de médecine interne et de pathologie vasculaire, Centre Hospitalier Lyon Sud, Université Claude Bernard Lyon 1, Lyon, France; ${ }^{3}$ Département de mathématiques et statistique, Université Laval, Québec, Canada

Correspondence to: Dr S Provencher, Centre de Pneumologie, Hôpital Laval 2725 Chemin Ste-Foy, Québec

P. Québec, G1V 4 G5 Canada; steve.provencher@crhl.ulaval. ca

Received 21 November 2008 Accepted 31 May 2009

Published Online First

11 June 2009

\title{
Natriuretic peptides and troponins in pulmonary embolism: a meta-analysis
}

\author{
J-C Lega, ${ }^{1,2}$ Y Lacasse, ${ }^{1}$ L Lakhal, ${ }^{1,3}$ S Provencher ${ }^{1}$
}

\section{ABSTRACT}

Background: The role of biomarkers such as B-type natriuretic peptides (BNP and NT-proBNP) and troponins in risk stratification of acute pulmonary embolism (APE) is still debated. A meta-analysis was performed to assess the association between raised natriuretic peptide levels, alone or in conjunction with troponins, and all-cause and APE-related mortality, serious adverse events and echographic right ventricular dysfunction.

Methods: MEDLINE and EMBASE databases were searched and conference abstracts were hand searched up to February 2008. Studies were included if a $2 \times 2$ table could be constructed based on natriuretic peptide results and at least one of the outcomes.

Results: Twenty-three studies were included (1127 patients). Raised natriuretic peptide levels were significantly associated with all-cause mortality (odds ratio (OR) 6.2; 95\% confidence interval (CI) 3.0 to 12.7), APE-related mortality (OR 5.0; $95 \% \mathrm{Cl} 2.2$ to 11.5 ) and serious adverse events (OR 6.7; 95\% Cl 3.9 to 11.6), with homogeneity across studies. Among patients with raised natriuretic peptide levels, increased serum troponins were associated with a further increase in the risk of adverse outcomes. Analysis of the accuracy of natriuretic peptides in detecting right ventricular dysfunction was limited by heterogeneity across studies. BNP appeared to have better sensitivity and specificity than NT-proBNP in detecting right ventricular dysfunction.

Conclusions: Raised levels of B-type natriuretic peptides identified a subset of patients with APE at higher risk of adverse outcomes. Among patients with raised natriuretic peptide levels, increased troponins were found to be an independent prognostic marker. The results of this metaanalysis may have important clinical implications in the management of APE.

Acute pulmonary embolism (APE) may present with a wide spectrum of manifestations ranging from lack of symptoms to massive embolism resulting in right ventricular failure and sudden death. ${ }^{12}$ Although most patients initially have normal blood pressure, some patients rapidly deteriorate and develop systemic hypotension, cardiogenic shock and death despite appropriate anticoagulation. Early risk stratification is the cornerstone of the modern management of APE as it largely influences patient management. ${ }^{12}$ Patients at risk for adverse clinical events will require close monitoring or even more aggressive therapy, whereas early discharge and outpatient treatment will be considered for those at low risk. ${ }^{2}$ Among patients with normal blood pressure on admission, major adverse clinical events attributable to APE are generally confined to patients with echocardiographic signs of right ventricular dysfunction. However, major drawbacks of echocardiography include its limited round-the-clock availability, occasional poor imaging quality and absence of consensus criteria for right ventricular overload. ${ }^{1}$

A number of biomarkers, including natriuretic peptides and cardiac troponins, have recently raised interest for risk stratification in patients with APE. Natriuretic peptides are secreted by the heart in response to pressure or volume overload and are also influenced by patients' age, body mass index and renal function. ${ }^{3}$ In the setting of APE, increases in natriuretic peptide levels (BNP and NT-proBNP) are presumably related to enhanced right ventricular shear stress and right ventricular dysfunction. ${ }^{4}$ Increased cardiac troponin $\mathrm{T}$ and $\mathrm{I}$, two related muscular proteins released in response to myocardial ischaemia, were recently shown to be associated with higher mortality in APE. ${ }^{5}$ The objectives of this meta-analysis were to assess (1) the prognostic significance of BNP and NT-proBNP alone or in conjunction with troponins, and (2) the diagnostic accuracy of natriuretic peptides in detecting right ventricular dysfunction in patients with APE.

\section{METHODS}

The methods that we used were in accordance with the recommendations of the Meta-analysis of Observational Studies in Epidemiology (MOOSE) Group. ${ }^{6}$

\section{Literature search}

We searched EMBASE (1974-February 2008) and MEDLINE (1966-February 2008) for original articles published in any language. Search criteria combined free text search, exploded MESH/EMTREE terms and all synonyms of pulmonary embolism and brain natriuretic peptides (see further details in online supplement). We also searched for additional articles from the reference list of relevant papers obtained from the electronic search. In addition, the grey literature was explored by hand searching the conference abstracts of the American Heart Association, American College of Cardiology, European Society of Cardiology, American Thoracic Society, American College of Chest Physicians, European Respiratory Society and British Thoracic Society from January 1999 to February 2008.

\section{Study selection}

Observational studies were included if they reported on patients with an objective diagnosis of APE, and if a $2 \times 2$ table could be constructed based on BNP or NT-proBNP results and at least one of four outcomes: all-cause mortality, APErelated mortality, serious adverse events and/or 
right ventricular dysfunction. All-cause mortality was considered as the primary outcome. Serious adverse events were defined as the composite of death and any of the following: shock, need for thrombolysis, need for catheter fragmentation, need for surgical embolectomy, endotracheal intubation, catecholamine infusion for sustained hypotension, cardiopulmonary resuscitation or recurrent pulmonary embolism.

Two reviewers (JCL, SP) independently applied these criteria to the titles and abstracts of all citations obtained. When there was any possibility that it might be relevant, the paper was retrieved and independently assessed by the same reviewers for a final decision about its inclusion into the meta-analysis. Throughout this process the reviewers were blinded to authors' names, journal and year of publication of the papers. Those published in languages other than English and French were translated into French. When we identified studies that had been reported in multiple papers, the analysis was limited to the largest cohort unless the necessary data had appeared only in another paper. Any disagreement was resolved by consensus. A $\log$ of reasons for rejection of citations identified from the searches was kept. The agreement between the two primary reviewers was measured using the quadratic weighted kappa statistic. $^{7}$

We determined "a priori" that the effect of publication bias should be minor if the plot of the magnitude of risk in each study (ie, odds ratio (OR)) versus its precision estimate (ie, standard error of OR) showed a roughly symmetrical funnel shape. ${ }^{8}$ We also formally tested the presence of publication bias using the standard error- and study size-based funnel plot and related asymmetry tests. ${ }^{9}$

\section{Assessment of methodological quality}

The methodological quality of the selected studies was evaluated by systematically considering three important sources of bias in observational studies: ${ }^{10}$ (1) whether the study included consecutive patients (selection bias); (2) whether the professionals who influenced the outcomes (eg, need for thrombolysis) were blinded to the natriuretic peptide result at study entry (information bias); and (3) whether comorbidities which might influence BNP or NT-proBNP levels and accuracy (eg, renal failure or chronic heart failure) were included (confounding bias). Each of these three criteria was evaluated separately.

\section{Information extraction}

In addition to the data related to natriuretic peptides alone, the same reviewers independently noted the results when cardiac troponin levels were measured in conjunction with natriuretic peptides. This meta-analysis therefore differed from that of Becattini et $a l^{5}$ who studied the value of cardiac troponins alone in APE. The abstracted information for each study included: (1) patients' characteristics (number of patients, mean age, gender distribution, methods for diagnosis of pulmonary embolism, haemodynamic status at study entry, length of follow-up); (2) test methods (assay, manufacturer, diagnostic threshold, time between admission and measurement); and (3) number of patients with or without the outcome of interest among those with positive or negative BNP, NT-proBNP and troponin when available. In cases of missing data, the authors were contacted for additional information.

\section{Meta-analysis}

In the main analysis we considered increased natriuretic peptide levels as a risk factor for adverse outcome. Accordingly, for each study we constructed $2 \times 2$ tables for each outcome at a given natriuretic peptide threshold level. All-cause mortality and APErelated mortality were considered separately. We also performed specific analyses of studies including only haemodynamically stable patients. When several thresholds were reported in the same studies, the one that approached the most frequently used threshold across studies was selected. The ORs were weighted by the inverse of their variance and combined according to a random effects model. ${ }^{11}$ Homogeneity was tested with Cochran's $\chi^{2}$ and $I^{2}$ tests. Statistically significant heterogeneity was considered present at $\mathrm{p}<0.10$ and $\mathrm{I}^{2}>50 \%{ }^{12}$

We also conducted a meta-analysis of the studies that assessed the combination of natriuretic peptides and troponins to predict adverse outcome in APE. In order to explore the added prognostic value of cardiac troponins over natriuretic peptides, patients with both positive natriuretic peptides and troponins were compared with those with positive natriuretic peptides and negative troponins.

We decided "a priori" to conduct subgroup analyses to identify sources of heterogeneity (if any) in the main analysis. Separate analyses were planned for studies (1) that assessed BNP and NT-proBNP assays; (2) that included patients with haemodynamic instability at study entry; and (3) that limited their analysis to short-term events ( $<6$ weeks). Subgroup analyses were also conducted according to the criteria of methodological quality described above. The meta-analyses were performed with Review Manager (Version 4.2, The Cochrane Collaboration).

In secondary analyses we considered the measurement of natriuretic peptides as a diagnostic test for right ventricular dysfunction. For each study a receiver operating characteristics (ROC) curve was constructed from the true positive rate (sensitivity) and the false positive rate (1 - specificity) at the reported threshold levels of natriuretic peptide. The ROC curves were then pooled with an additional random effect term. ${ }^{11}{ }^{13} \mathrm{We}$ computed the area under the curve that indicated the probability that a random pair of patients would be correctly classified as to their disease state. ${ }^{14}$ In addition, for each assay we calculated the pooled sensitivity, specificity and the corresponding likelihood ratios at the most frequently used threshold value. ${ }^{13}$ All the secondary analyses were performed with R software 2.5.1 (www.r-project.org).

\section{RESULTS}

\section{Literature search/agreement studies}

Two hundred and twenty-two separate publications were retrieved (fig 1). Both primary reviewers agreed to include 19 independent cohorts $^{4}{ }^{15-32}$ that contributed to 23 separate studies $^{4}{ }^{15-36}$ (quadratic weighted kappa 0.79 ; 95\% confidence interval (CI) 0.43 to 1). Two studies assessed the value of BNP and NT-proBNP in the same cohort. ${ }^{24}{ }^{36}$ Three articles ${ }^{33-35}$ reported on the same patients as those included in larger studies; ${ }^{18-20}$ these three articles were included only to perform specific analyses such as mortality in haemodynamically stable patients. Two other studies that were suspected of minimal overlap ( $<5 \%$ of patients) with each other that could not be confirmed by contact with the authors were also included. ${ }^{22}{ }^{26}$ The reasons for exclusion are shown in fig 1 . No indication of publication bias was found from the visual inspection of the funnel plot (fig 2) and from the standard error- and study size-based funnel plot and related asymmetry tests (both $\mathrm{p}=0.11$ ). 
Figure 1 Flow diagram for study selection.
222 citations retrieved from Pubmed, Embase, conference abstracts, and hand search

130 titles excluded

85 review papers

19 diagnostic value of natriuretic peptides

5 other biomarkers

6 case reports

6 editorials

5 letters

2 guidelines

1 animal study

1 report of the same patients

\section{2 papers undergoing full-text revision}

\begin{tabular}{|c|c|}
\hline 56 papers excluded after full text revision \\
17 report on the same patients \\
11 diagnostic value of natriuretic peptides or \\
other biomarkers \\
13 review papers \\
7 letters \\
6 editorials \\
2 case reports \\
\cline { 2 - 3 }
\end{tabular}

36 studies with acute pulmonary embolism and natriuretic peptide assessment at admission

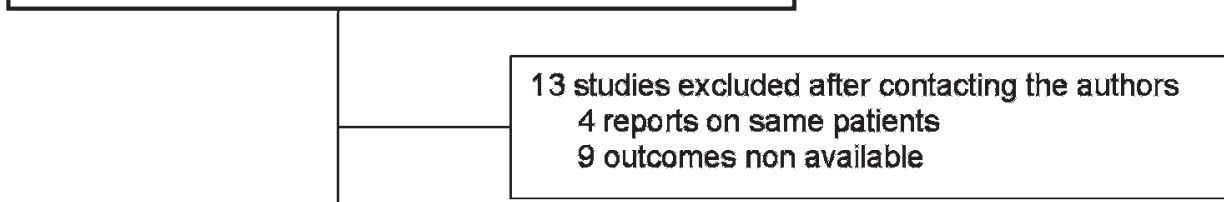

23 studies included in the meta-analysis

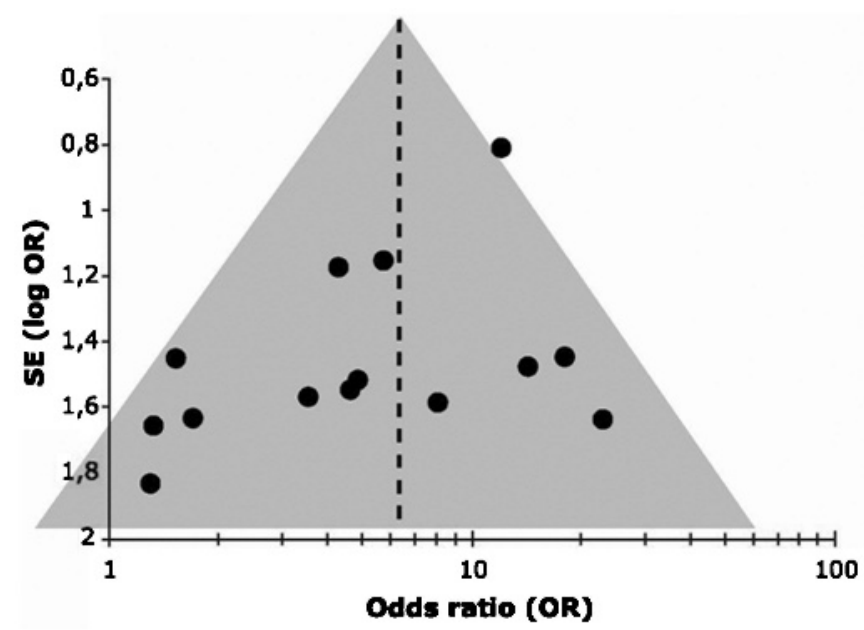

Figure 2 Study of publication bias: funnel plot for the primary outcome of the meta-analysis (all-cause mortality). OR, odds ratio; SE ( $\log O R$ ), standard error of $\log$ OR. The studies with no events ${ }^{17}{ }^{31}$ could not be represented.

\section{Selected studies}

The characteristics of the selected studies are shown in table 1S in the online supplement. Six studies assessed the combination of natriuretic peptides and troponins to predict adverse outcome $^{15} 1928323335$ and six studies included haemodynamically stable patients only. ${ }^{17} 1821283335$ The length of follow-up ranged from hospital discharge to 365 days following admission to hospital. Right ventricular dysfunction was defined as right ventricular hypokinesis of the free wall in three studies, ${ }^{15}{ }^{4} 36$ severity of tricuspid regurgitation in one study ${ }^{16}$ right ventricular dilatation in one study ${ }^{31}$ and by a composite criteria in 10 studies, all including increased RV/LV end-diastolic diameter ratio. ${ }^{4} 1720-2325262832$

\section{Assessment of methodological quality}

All 23 studies included consecutive patients with APE and none reported any patients lost to follow-up. The physicians who influenced the outcomes and the echographists were blinded to the biomarker results in $10^{17} 20-22262831323435$ and $13^{4} 15-1720-23$ 2526283132 studies, respectively. Patients with comorbidities susceptible to influence natriuretic peptides levels were excluded 
in 10 studies. $^{415} 1618212325283133$ In one study, no data regarding the methodology used was available. ${ }^{27}$ The validity assessment of the included studies is shown in table $2 \mathrm{~S}$ in the online supplement.

\section{Natriuretic peptide and troponin assays}

The value of BNP and NT-proBNP was assessed in $15^{4} 15161821$ 23-252728 30-34 and 8 studies, ${ }^{17} 19202226293536$ respectively. In all studies the biomarkers were measured at patient admission. For the BNP studies four different assays were used, whereas only one NT-proBNP assay was used. Threshold levels defining positive and negative results were determined "a priori" in 5 studies"17 19232426 and "a posteriori" in 18 studies, mainly by ROC analysis. For the seven studies that reported the results according to multiple threshold levels, ${ }^{18} 202123242834$ the following range of thresholds was chosen to facilitate betweenstudy comparisons: BNP: $80-100 \mathrm{ng} / \mathrm{ml}$ for the Biosite Diagnostics assay and $35-75 \mathrm{ng} / \mathrm{ml}$ for the Shionogi assay; NT-proBNP: $600-1000 \mathrm{ng} / \mathrm{ml}$ for the Roche assay. Troponins $I^{15} 192832$ and $\mathrm{T}^{33}{ }^{35}$ were assessed by four and two studies, respectively. Three different assays were used with different thresholds ranging from 0.01 to $0.1 \mu \mathrm{g} / \mathrm{l}$. The test methods used for troponins or BNP were not available in two studies. ${ }^{27}{ }^{33}$ The characteristics of the natriuretic peptide and troponin assays are shown in table $3 \mathrm{~S}$ in the online supplement.

\section{Meta-analysis}

\section{Natriuretic peptides in APE prognosis}

The association between raised natriuretic peptide levels and adverse outcome in APE is shown in table 1. Overall, 52\% (587/ 1127) of patients with APE had raised natriuretic peptides. Increased levels of natriuretic peptides were associated with an increased risk for all-cause mortality (fig 3), APE-related mortality and serious adverse events (figs $1 \mathrm{~S}$ and $2 \mathrm{~S}$ in the online supplement). The prognostic significance of raised natriuretic peptide levels was similar in studies that only included haemodynamically stable patients for all-cause mortality (OR 8.2; CI 2.5 to 26.4), APE-related mortality (OR 6.6; CI 1.7 to 25.6) and serious adverse events (OR 15.6; CI 3.0 to 81.9). Homogeneity was found across the studies in the meta-analyses for these outcomes so no further subgroup analyses were performed.

Cardiac troponins in addition to natriuretic peptides in APE prognosis Among natriuretic peptide-positive patients, 46\% (103/222) also had positive troponin values. Only 4\% (14/383) of patients were positive for troponins and negative for natriuretic peptides. Among natriuretic peptide-positive patients, raised troponin levels were associated with further increase in risk for all-cause mortality, APE-related mortality and serious adverse events (table 2). The results were still significant in haemodynamically stable patients with homogeneity across studies for all-cause mortality (OR 6.9; CI 2.3 to 20.7), ${ }^{28}{ }^{33} 35$ APE-related mortality (OR 8.4; CI 2.1 to 33.4), ${ }^{28} 3335$ but not for serious adverse events (OR 15.5; CI 0.8 to 284.7). ${ }^{28}$ The rate of all-cause mortality, APE-related mortality and serious adverse events in natriureticand troponin-negative patients were $0.2 \%(1 / 443), 0 \%(0 / 341)$ and $1.6 \%(7 / 443)$, respectively.

Natriuretic peptide for the diagnosis of right ventricular dysfunction A total of 899 patients with right ventricular dysfunction assessment contributed to the analysis. The overall prevalence of right ventricular dysfunction was $41 \%$ (CI $37 \%$ to $44 \%$ ). The interpretation of the risk of right ventricular dysfunction with an increased natriuretic peptide level was limited by our finding of significant heterogeneity among the 14 studies that contributed to this meta-analysis (table 1 and fig $3 \mathrm{~S}$ in the online supplement). None of the subgroup analyses that we planned "a priori" satisfactorily explained this heterogeneity (see table 4S in the online supplement).

The summary ROC curve is shown in fig 4. For BNP, the area under the curve was 0.92 (CI 0.88 to 0.94 ). Due to the paucity of studies, we could not compute a reliable area under the curve for NT-proBNP. Nevertheless, visual inspection of fig 4 suggested that BNP was more accurate than NT-proBNP in the diagnosis of right ventricular dysfunction. This was substantiated by the pooled sensitivities and specificities. For the BNP Triage Biosite assay, pooled sensitivity and specificity at the threshold of $90 \mathrm{ng} / \mathrm{ml}$ were $96 \%$ (CI 93\% to 99\%) and 91\% (CI 86\% to 96\%) respectively ( $p_{\text {homogeneity }}=0.73, \mathrm{I}^{2}=0 \%$ ), which correspond to positive and negative likelihood ratios of 10.7 and 0.04 , respectively. For the NT-proBNP Roche assay, pooled sensitivity and specificity at a threshold of $1000 \mathrm{ng} / \mathrm{ml}$ were $82 \%(76 \%$ to $88 \%$ ) and $59 \%$ (CI $52 \%$ to $66 \%$ ) respectively, with homogeneity among studies ( $p_{\text {homogeneity }}=0.25, \mathrm{I}^{2}=27 \%$ ), which correspond to positive and negative likelihood ratios of 2.0 and 0.31 , respectively.

\section{DISCUSSION}

Our meta-analysis shows that raised B-type natriuretic peptide levels are associated with increased risk of mortality, serious

Table 1 Natriuretic peptides in APE prognosis: primary results of the meta-analysis

\begin{tabular}{|c|c|c|c|c|c|c|}
\hline \multirow[b]{2}{*}{ Outcome } & \multirow[b]{2}{*}{ No of studies } & \multirow[b]{2}{*}{ References } & \multirow[b]{2}{*}{ Proportion of events $(95 \% \mathrm{CI})$} & \multirow[b]{2}{*}{ Pooled OR (95\% CI) } & \multicolumn{2}{|c|}{ Homogeneity } \\
\hline & & & & & p Value & $I^{2}(\%)$ \\
\hline All-cause mortality & 16 & $4,15-22,24,27-32$ & $\begin{array}{l}(+): 62 / 491,12.6 \%(9.6 \% \text { to } 15.5 \%) \\
(-): 5 / 433,1.1 \%(0.1 \% \text { to } 2.1 \%)\end{array}$ & $6.2(3.0$ to 12.7$)$ & 0.96 & 0.0 \\
\hline APE-related mortality & 14 & $\begin{array}{l}4,15-18,21,24,27-31 \\
34,35\end{array}$ & $\begin{array}{l}(+): 40 / 378,10.6 \%(7.9 \% \text { to } 14.1 \%) \\
(-): 3 / 298,1.0 \%(0.3 \% \text { to } 2.9 \%)\end{array}$ & $5.0(2.2$ to 11.5$)$ & 0.97 & 0.0 \\
\hline $\begin{array}{l}\text { Serious adverse } \\
\text { events }\end{array}$ & 9 & $\begin{array}{l}15,19,21,22,24,26,28, \\
32,35\end{array}$ & $\begin{array}{l}(+): 115 / 416,27.6 \%(23.4 \% \text { to } 32.0 \%) \\
(-): 17 / 319,5.3 \%(2.8 \% \text { to } 7.7 \%)\end{array}$ & 6.7 (3.9 to 11.6$)$ & 0.83 & 0.0 \\
\hline $\begin{array}{l}\text { Right ventricular } \\
\text { dysfunction }\end{array}$ & 14 & $\begin{array}{l}4,15-17,20-26,28,31 \\
32\end{array}$ & $\begin{array}{l}(+): 352 / 487,72.3 \% \text { (68.3\% to } 76.3 \%) \\
(-): 71 / 412,17.2 \%(13.6 \% \text { to } 20.9 \%)\end{array}$ & $24.2(11.4$ to 51.3$)$ & 0.001 & 61.1 \\
\hline
\end{tabular}

$\mathrm{APE}$, acute pulmonary embolism; $\mathrm{Cl}$, confidence interval; $\mathrm{OR}$, odds ratio.

$(+)$ indicates the proportion of patients with the outcome of interest among those with positive natriuretic peptides; $(-)$ indicates the proportion of patients with the outcome of interest among those with negative natriuretic peptides. 


\begin{tabular}{|c|c|c|c|c|c|c|}
\hline \multirow{3}{*}{$\begin{array}{l}\text { Study } \\
\text { or sub-category } \\
01 \text { BNP }\end{array}$} & \multicolumn{2}{|c|}{ Natriuretic peptide } & \multirow[b]{2}{*}{$\begin{array}{c}\text { OR (random) } \\
95 \% \mathrm{Cl}\end{array}$} & \multirow[b]{2}{*}{$\begin{array}{l}\text { Weight } \\
\%\end{array}$} & \multirow{2}{*}{\multicolumn{2}{|c|}{$\begin{array}{c}\text { OR (random) } \\
95 \% \mathrm{Cl}\end{array}$}} \\
\hline & $\begin{array}{c}\text { positive } \\
n N\end{array}$ & $\begin{array}{c}\text { negative } \\
\text { RN }\end{array}$ & & & & \\
\hline & & & & & & \\
\hline Burazor 2005 & $3 / 17$ & $0 / 3$ & & 5.05 & 1.69 & $10.07,40.831$ \\
\hline Enea 2004 & $4 / 20$ & $0 / 6$ & & 5.47 & 3.55 & {$[0.17,75.58]$} \\
\hline Klely 2005 & $3 / 6$ & $0 / 11$ & & 5.02 & 23.00 & $10.94,561.79]$ \\
\hline Kruger 2004 & $1 / 17$ & $1 / 25$ & $=$ & 6.34 & 1.50 & $10.09,25.75]$ \\
\hline Kucher 2003 & $4 / 32$ & $1 / 41$ & 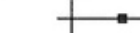 & 10.18 & 5.71 & {$[0.61,53.89]$} \\
\hline Lee 2008 & $2 / 14$ & $0 / 20$ & 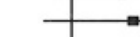 & 5.28 & 8.20 & {$[0.36,185.10]$} \\
\hline Logeart 2007 & $1 / 47$ & $0 / 20$ & - & 4.87 & 1.32 & {$[0.05,33.86]$} \\
\hline Pieralli 2006 & $4 / 41$ & $0 / 20$ & 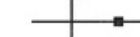 & 5.81 & 4.92 & $10.25,95.99]$ \\
\hline Sanchez 2005 & $3 / 43$ & $1 / 59$ & 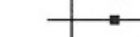 & 9.70 & 4.35 & $10.44,43.331$ \\
\hline Ten Wolde 2003 & $9 / 36$ & $2 / 74$ & 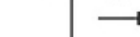 & 20.15 & 12.00 & {$[2.44,59.12]$} \\
\hline Yetkin 2007 & $0 / 7$ & $0 / 11$ & & & & ot estinable \\
\hline Subtotal $(95 \% \mathrm{Cl})$ & 280 & 290 & & 77.86 & 5.42 & {$[2.41,12.21]$} \\
\hline Total events: 34 (p & & & & & & \\
\hline Test for heterogen & $9\langle P=0.91$ & & & & & \\
\hline Test for overall ef 1 & 001) & & & & & \\
\hline 02 NT-proBNP & & & & & & \\
\hline Binder 2005 & $7 / 67$ & $0 / \$ 7$ & & 6.16 & 14,26 & {$[0.80,255.33]$} \\
\hline Kostrubiec 2007 & $17 / 81$ & $0 / 32$ & & 6.34 & 17.64 & {$[1.03,302.62]$} \\
\hline Laiho 2008 & $0 / 33$ & $0 / 18$ & & & & ot estimable \\
\hline Maziere 2007 & $3 / 26$ & $0 / 34$ & & 5.66 & 10.28 & {$[0.51,208.32]$} \\
\hline Meyer 2007 & $1 / 4$ & $0 / 2$ & & 3.98 & 2.14 & {$[0.06,27.54]$} \\
\hline Subtotal $(95 \% \mathrm{Cl})$ & 211 & 143 & & 22.14 & 9.91 & {$[2.16,45.39]$} \\
\hline Total events: 28 (p & & & & & & \\
\hline Test for heterogen & $3 \zeta P=0.81$ & & & & & \\
\hline Test for overall eft & 03) & & & & & \\
\hline Total $(95 \% \mathrm{Cl})$ & 491 & 433 & & 100.00 & 6.20 & {$[3.03,12.68]$} \\
\hline Total events: 62 (p & & & & & & \\
\hline Test for heterogen & $13\langle P=0.9$ & & & & & \\
\hline Test for overall eft & $0001)$ & & & & & \\
\hline
\end{tabular}

Figure 3 Meta-analysis of B-type natriuretic peptides BNP and NT-proBNP to predict all-cause mortality in acute pulmonary embolism. Data of studies with patient overlap were not pooled together in the overall odds ratio (OR). ${ }^{19}{ }^{34}$

adverse events and right ventricular dysfunction in APE. In most analyses the results were consistent across studies regardless of the patient's haemodynamic status at admission and the presence of medical conditions with the potential to influence natriuretic peptide levels such as chronic heart failure and renal failure. Among patients with raised natriuretic peptide levels, increased troponin levels were also found to be an independent prognostic marker of morbidity and mortality in APE. Conversely, patients with negative natriuretic peptides and troponins were at very low risk of complications.
In the meta-analysis, BNP appeared to be more accurate than NT-proBNP for detecting right ventricular dysfunction. Similar results were recently reported by others in a meta-analysis for the diagnosis of heart failure. ${ }^{37}$ Several physiopathological processes may explain the higher accuracy of BNP, including the fact that the NT-proBNP assay is affected to a greater extent by glomerular filtration rate. ${ }^{3}$ Another potential explanation is the absence of consensus for right ventricular dysfunction definition, ${ }^{1}$ which differed among the studies included in the analysis.

Table 2 Increased cardiac troponins in patients with positive natriuretic peptides: results of the meta-analysis

\begin{tabular}{|c|c|c|c|c|c|c|}
\hline \multirow[b]{2}{*}{ Outcome } & \multirow{2}{*}{$\begin{array}{l}\text { No of } \\
\text { studies }\end{array}$} & \multirow[b]{2}{*}{ References } & \multirow[b]{2}{*}{ Proportion of events $(95 \% \mathrm{CI})$} & \multirow[b]{2}{*}{ Pooled OR (95\% CI) } & \multicolumn{2}{|c|}{ Homogeneity } \\
\hline & & & & & $p$ value & $I^{2}(\%)$ \\
\hline All-cause mortality & 6 & $15,19,28,32,33,35$ & $\begin{array}{l}(+): 37 / 97,38.1 \%(28.4 \% \text { to } 47.9 \%) \\
(-): 7 / 119,5.9 \%(1.7 \% \text { to } 10.1 \%)\end{array}$ & 8.0 (3.0 to 21.4$)$ & 0.72 & 0.0 \\
\hline $\begin{array}{l}\text { APE-related } \\
\text { mortality }\end{array}$ & 4 & $15,28,33,35$ & $\begin{array}{l}(+): 13 / 74,17.6 \%(8.8 \% \text { to } 26.3 \%) \\
(-): 2 / 79,2.5 \%(0.0 \% \text { to } 5.9 \%)\end{array}$ & $8.6(2.2$ to 34.1$)$ & 0.57 & 0.0 \\
\hline $\begin{array}{l}\text { Serious adverse } \\
\text { outcome }\end{array}$ & 4 & $15,19,28,32$ & $\begin{array}{l}(+): 27 / 79,34.2 \%(23.7 \% \text { to } 44.7 \%) \\
(-): 8 / 49,16.3 \%(5.8 \% \text { to } 26.8 \%)\end{array}$ & 13.3 (2.4 to 74.2 ) & 0.83 & 0.0 \\
\hline $\begin{array}{l}\text { Right ventricular } \\
\text { dysfunction }\end{array}$ & 2 & 15,28 & $\begin{array}{l}(+): 44 / 50,88.0 \%(78.9 \% \text { to } 97.1 \%) \\
(-): 12 / 17,70.6 \%(50.8 \% \text { to } 90.3 \%)\end{array}$ & $1.67(0.4$ to 6.6$)$ & NA & NA \\
\hline
\end{tabular}

APE, acute pulmonary embolism; $\mathrm{Cl}$, confidence interval; NA, not applicable; OR, odds ratio.

$(+)$ indicates the proportion of patients with the outcome of interest among those with both positive troponins and natriuretic peptides; $(-)$ indicates the proportion of patients with the outcome of interest among those with negative troponins and positive natriuretic peptides. 


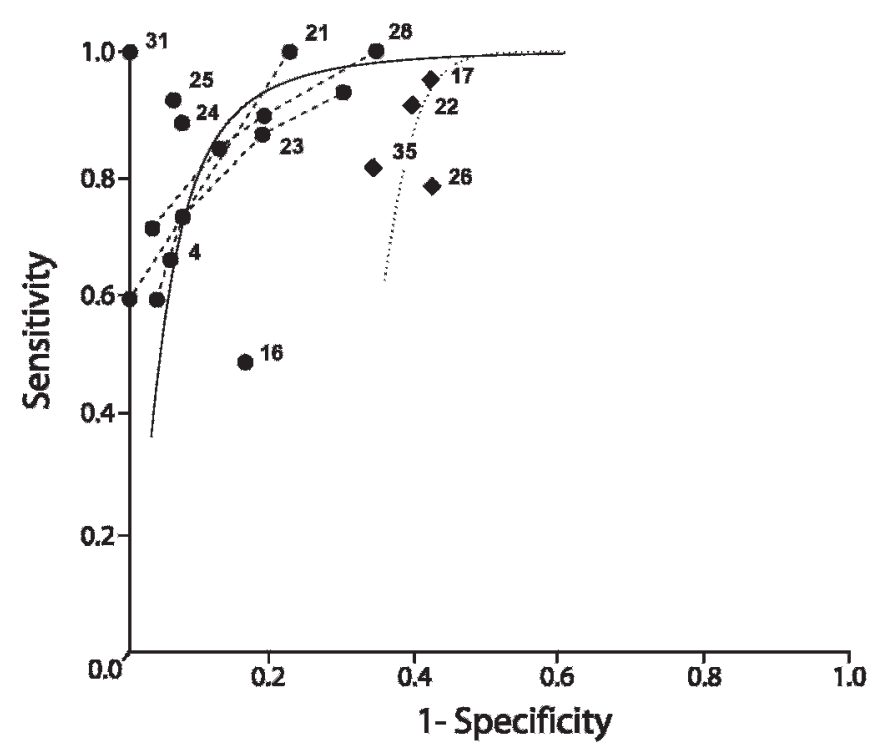

Figure 4 Estimation of natriuretic peptide accuracy by ROC curves. BNP studies are represented by circles and NT-proBNP studies by diamonds. Results from different cut-off points within the same study are joined by dotted lines. The studies are identified by their reference numbers.

In the subgroup analysis of studies that excluded patients with comorbidities which might influence natriuretic peptide levels and accuracy, increased natriuretic peptides tended to predict right ventricular dysfunction better than studies which included patients with these comorbidities (table 4S in online supplement). Although this difference did not reach statistical significance, we interpret it as a consequence of the confounding effect of renal and congestive heart failure. Notwithstanding this confounding effect, natriuretic peptides remained similarly accurate in predicting mortality and serious adverse events among patients with these conditions. The inclusion of patients with these comorbidities better reflects current clinical practice and enhances the external validity of the results.

The relation between natriuretic peptide level and prognosis in APE has recently been explored in four other systematic reviews. ${ }^{38-41}$ They differed from ours in several important methodological aspects. Their literature search was limited to the published literature and two considered only the English literature. ${ }^{39}{ }^{40}$ As a consequence, we included a larger number of studies by also searching the grey literature and contacting the authors when data were missing to complete the analysis. ${ }^{15-}$ 1727293132 A more important difference is that the authors inadvertently included the results of studies from totally or partially duplicated cohorts, ${ }^{19} 222433-3642-44$ corresponding to a significant proportion of their total sample size (17-28\%).

We acknowledge limitations to our systematic review that are inherent to the available data. First, the thresholds for natriuretic peptide positivity often differed across studies. In the main analysis, this precluded our computing of pooled sensitivities and specificities at given thresholds. We therefore limited the meta-analyses to the pooling of ORs. Only full access to individual data could have resolved this problem. Second, ORs provided by this meta-analysis are unadjusted for other risk factors of adverse events in APE, with the exception of impaired haemodynamic status. Third, the causes of deaths were not analysed in most studies. This situation may have influenced the rate of APE-related deaths. Finally, despite the fact that all authors were contacted when data were missing to complete our analysis, we estimated that 615 additional patients from published articles or meeting abstracts could not be included in the present analysis.

The results of our meta-analysis have important clinical implications in the management of APE. While massive APE is undoubtedly associated with poor prognosis and requires an aggressive therapeutic approach, the role of such treatment in submassive APE remains controversial. ${ }^{12}$ Increases in natriuretic peptide levels at admission clearly identify a subgroup of patients at higher risk of APE-related death, whatever their haemodynamic status. Patients with increased levels of both natriuretic peptides and troponins are at a particularly high risk of adverse outcomes. Also, natriuretic peptides appear to be especially helpful in identifying low-risk patients, given their very low positive rate among those with a poor outcome (table 1). Nevertheless, large-scale prospective randomised controlled trials are clearly necessary to define the precise role of cardiac biomarkers and the optimal cut-off values to select patients with APE who may benefit from thrombolysis or outpatient treatment. ${ }^{45}$

Acknowledgements: The authors thank Sylvie Martin for her technical support.

Funding: A scholarship fund was provided by the Ministère français de l'Éducation nationale, de l'Enseignement supérieur et de la Recherche. The Ministère was not otherwise involved in the study.

Competing interests: None.

Provenance and peer review: Not commissioned; externally peer reviewed.

\section{REFERENCES}

1. Torbicki A, Perrier A, Konstantinides S, et al. Guidelines on the diagnosis and management of acute pulmonary embolism: the Task Force for the Diagnosis and Management of Acute Pulmonary Embolism of the European Society of Cardiology (ESC). Eur Heart J 2008;29:2276-315.

2. Kearon C, Kahn S, Agnelli G, et al. Antithrombotic therapy of venous thromboembolic disease. American College of Chest Physicians Evidence-Based Clinical Practice Guidelines, 8th ed. Chest 2008;133:454-545S.

3. Daniels LB, Maisel AS. Natriuretic peptides. J Am Coll Cardiol 2007;50:2357-68.

4. Kruger S, Graf J, Merx MW, et al. Brain natriuretic peptide predicts right heart failure in patients with acute pulmonary embolism. Am Heart J 2004;147:60-5.

5. Becattini C, Vedovati MC, Agnelli G. Prognostic value of troponins in acute pulmonary embolism: a meta-analysis. Circulation 2007;116:427-33.

6. Stroup DF, Berlin JA, Morton SC, et al. Meta-analysis of observational studies in epidemiology: a proposal for reporting. Meta-analysis Of Observational Studies in Epidemiology (MOOSE) group. JAMA 2000;283:2008-12.

7. Kramer MS, Feinstein AR. Clinical biostatistics. LIV. The biostatistics of concordance. Clin Pharmacol Ther 1981;29:111-23.

8. Montori VM, Smieja M, Guyatt GH. Publication bias: a brief review for clinicians. Mayo Clin Proc 2000;75:1284-8.

9. Egger M, Davey Smith G, Schneider M, et al. Bias in meta-analysis detected by a simple, graphical test. BMJ (Clin Res Ed) 1997;315:629-34.

10. Grimes DA, Schulz KF. Bias and causal associations in observational research. Lancet 2002;359:248-52.

11. DerSimonian R, Laird N. Meta-analysis in clinical trials. Control Clin Trials 1986; 7:177-88.

12. Higgins JP, Thompson SG. Quantifying heterogeneity in a meta-analysis. Stat Med 2002;21:1539-58.

13. Moses LE, Shapiro D, Littenberg B. Combining independent studies of a diagnostic test into a summary ROC curve: data-analytic approaches and some additional considerations. Stat Med 1993;12:1293-316.

14. Hanley JA, McNeil BJ. The meaning and use of the area under a receiver operating characteristic (ROC) curve. Radiology 1982;143:29-36.

15. Enea I, Ceparano G, Mazzarella G, et al. [Biohumoral markers and right ventricular dysfunction in acute pulmonary embolism: the answer to thrombolytic therapy]. Ital Heart J Supp/ 2004;5:29-35.

16. Lee SJ, Lee JH, Park JY, et al. The prognostic role of B-type natriuretic peptide in acute pulmonary embolism. Tuberc Respir Dis 2006;60:540-7.

17. Laiho $\mathbf{M}$, Graner $\mathbf{M}$, Mustonen $\mathbf{P}$, et al. NT-proBNP is a sensitive marker for right ventricular dysfunction both in screening of patients with acute pulmonary embolism and in follow-up. Eur Heart J 2005;26:85.

18. ten Wolde M, Tulevski II, Mulder JW, et al. Brain natriuretic peptide as a predictor of adverse outcome in patients with pulmonary embolism. Circulation 2003;107:2082-4. 
19. Maziere F, Birolleau S, Medimagh S, et al. Comparison of troponin I and N-terminalpro B-type natriuretic peptide for risk stratification in patients with pulmonary embolism. Eur J Emerg Med 2007;14:207-11.

20. Kostrubiec M, Pruszczyk P, Kaczynska A, et al. Persistent NT-proBNP elevation in acute pulmonary embolism predicts early death. Clin Chim Acta 2007;382:124-8.

21. Pieralli F, Olivotto I, Vanni S, et al. Usefulness of bedside testing for brain natriuretic peptide to identify right ventricular dysfunction and outcome in normotensive patients with acute pulmonary embolism. Am J Cardiol 2006;97:1386-90.

22. Binder L, Pieske B, Olschewski M, et al. N-terminal pro-brain natriuretic peptide or troponin testing followed by echocardiography for risk stratification of acute pulmonary embolism. Circulation 2005;112:1573-9.

23. Pascu A, Radoi M, Coculescu M. Plasma brain natriuretic peptide (BNP) increase is associated with acute right ventricular dysfunction in pulmonary embolism. Acta Endocrinol 2005;1:393-410.

24. Kucher N, Printzen G, Goldhaber SZ. Prognostic role of brain natriuretic peptide in acute pulmonary embolism. Circulation 2003;107:2545-7.

25. Yardan T, Altintop L, Baydin A, et al. B-type natriuretic peptide as an indicator of right ventricular dysfunction in acute pulmonary embolism. Int J Clin Pract 2008;62:1177-82.

26. Lankeit M, Kempf T, Dellas $\mathbf{C}$, et al. Growth differentiation factor-15 for prognostic assessment of patients with acute pulmonary embolism. Am J Respir Crit Care Med 2008;177:1018-25

27. Burazor I, Zivkovic M, Djordjevic J, et al. Brain natriuretic peptide in patients with acute pulmonary embolism. European Respiratory Society 15th Annual Conference, Copenhagen, 2005, abstract \#1818 (on CD-ROM)

28. Logeart D, Lecuyer $\mathrm{L}$, Thabut $\mathrm{G}$, et al. Biomarker-based strategy for screening right ventricular dysfunction in patients with non-massive pulmonary embolism. Intensive Care Med 2007;33:286-92.

29. Meyer B, Huelsmann M, Wexberg P, et al. N-terminal pro-B-type natriuretic peptide is an independent predictor of outcome in an unselected cohort of critically ill patients. Crit Care Med 2007;35:2268-73.

30. Kiely DG, Kennedy NS, Pirzada 0, et al. Elevated levels of natriuretic peptides in patients with pulmonary thromboembolism. Respir Med 2005;99:1286-91.

31. Yetkin 0, Aksoy $\mathrm{Y}$, Turhan $\mathrm{H}$, et al. [Value of plasma BNP levels as a prognostic marker in lung and heart disorders]. Tuberk Toraks 2007;55:225-30.

32. Sanchez 0, Ricard G, Wermert D, et al. Pronostic value of echocardiography, BNP and cardiac troponin in normotensive patients with pulmonary embolism. European
Respiratory Society 15th Annual Conference, Copenhagen, 2005, abstract \#1828 (on CD-ROM).

33. Tulevski II, ten Wolde M, van Veldhuisen DJ, et al. Combined utility of brain natriuretic peptide and cardiac troponin T may improve rapid triage and risk stratification in normotensive patients with pulmonary embolism. Int J Cardiol 2007;116:161-6.

34. Ray P, Maziere F, Medimagh S, et al. Evaluation of B-type natriuretic peptide to predict complicated pulmonary embolism in patients aged 65 years and older: brief report. Am J Emerg Med 2006;24:603-7.

35. Kostrubiec M, Pruszczyk P, Bochowicz A, et al. Biomarker-based risk assessment model in acute pulmonary embolism. Eur Heart J 2005;26:2166-72.

36. Kucher N, Printzen G, Doernhoefer T, et al. Low pro-brain natriuretic peptide levels predict benign clinical outcome in acute pulmonary embolism. Circulation 2003; 107:1576-8.

37. Ewald B, Ewald D, Thakkinstian A, et al. Meta-analysis of B type natriuretic peptide and $\mathrm{N}$-terminal pro $\mathrm{B}$ natriuretic peptide in the diagnosis of clinical heart failure and population screening for left ventricular systolic dysfunction. Intern Med J 2008;38:101-13.

38. Sanchez 0, Trinquart L, Colombet I, et al. Prognostic value of right ventricular dysfunction in patients with haemodynamically stable pulmonary embolism: a systematic review. Eur Heart J 2008;29:1569-77.

39. Klok FA, Mos IC, Huisman MV. BNP levels in the prediction of adverse outcome in patients with pulmonary embolism: a meta-analysis. Am J Respir Crit Care Med 2008;178:425-30.

40. Cavallazzi R, Nair A, Vasu T, et al. Natriuretic peptides in acute pulmonary embolism: a systematic review. Intensive Care Med 2008:34:2147-56.

41. Coutance G, Le Page 0, Lo T, et al. Prognostic value of brain natriuretic peptide in acute pulmonary embolism. Crit Care 2008;12:R109.

42. Pruszczyk P, Kostrubiec $\mathrm{M}$, Bochowicz $\mathrm{A}$, et al. N-terminal pro-brain natriuretic peptide in patients with acute pulmonary embolism. Eur Respir $J$ 2003;22:649-53.

43. Puls $\mathbf{M}$, Dellas $\mathrm{C}$, Lankeit $\mathrm{M}$, et al. Heart-type fatty acid-binding protein permits early risk stratification of pulmonary embolism. Eur Heart J 2007;28:224-9.

44. Tulevski II, Hirsch A, Sanson BJ, et al. Increased brain natriuretic peptide as a marker for right ventricular dysfunction in acute pulmonary embolism. Thromb Haemost 2001;86:1193-6.

45. Davies CW, Wimperis J, Green ES, et al. Early discharge of patients with pulmonary embolism: a two-phase observational study. Eur Respir J 2007;30:708-14.

\section{Lung alert}

\section{WISP-1, a novel target for treatment of pulmonary fibrosis}

Idiopathic pulmonary fibrosis (IPF) is characterised by formation of fibroblast foci and deposition of extracellular matrix (ECM) in the lung interstitium. This results in distorted lung architecture, impaired gas exchange and reduced respiratory function. Impaired crosstalk between alveolar type 11 (AT11) cells and subepithelial fibroblasts has previously been shown to contribute to ECM deposition in IPF.

This study investigated the gene regulatory networks behind AT11 cell dysfunction in IPF. Genetic analyses highlighted WNT-inducible signalling protein-1 (WISP-1) as a key mediator of AT11 cells. WISP-1 was highly upregulated in AT11 cells in a mouse model of fibrosis and also in human lung tissue from patients with IPF.

The investigators treated murine primary AT11 cells with recombinant WISP-1 and induced epithelial-mesenchymal transition (EMT). EMT is recognised as a possible mechanism underlying the formation of fibroblast foci that occurs in IPF.

Recombinant WISP-1 treatment of lung fibroblasts in vitro led to increased ECM deposition. Furthermore, WISP-1 neutralisation resulted in attenuation of lung fibrosis in mouse models as evidenced by decreased lung ECM deposition. A marked reduction in expression of genes associated with fibrosis and reversal of EMT gene expression was noted. Interestingly, this was shown to partially restore normal lung function and significantly improve survival.

Currently available treatment options for IPF are limited. This study puts forward WISP-1 as a novel potential therapeutic target in IPF. Whether or not the findings in mouse models will translate to humans remains to be seen.

- Konigshoff M, Kramer M, Balsara N, et al. WNT1-inducible signaling protein-1 mediates pulmonary fibrosis in mice and is upregulated in humans with idiopathic pulmonary fibrosis. J Clin Invest 2009;119:772-87.

\section{A Singanayagam}

Correspondence to: Dr A Singanayagam, FY1, Charing Cross Hospital, London, UK; anika.singa@gmail.com

Provenance and peer review: Not commissioned; not externally peer reviewed.

Thorax 2009;64:875. doi:10.1136/thx.2009.121020 